\title{
Educating Future Medical Professionals with the Fundamentals of Law and Ethics
}

\author{
Puteri Nemie $\mathrm{JK}^{\text {a }}$ Ariff Osman $\mathrm{HO}^{\mathrm{b}}$, Ramizah WM ${ }^{\mathrm{a}}$ \\ ${ }^{a}$ Ahmad Ibrahim Kulliyyah of Laws, International Islamic University Malaysia, Jalan Gombak, Selangor. \\ ${ }^{b}$ Kulliyyah of Medicine, International Islamic University, Bandar Indera Mahkota, 25200 Kuantan, Pahang
}

\begin{abstract}
The increasing awareness amongst the society on medico-legal issues as well as the growth of consumerist attitude towards the provision of medical services has caused the medical profession to be subjected to vociferous criticism if they do not meet rising expectations of the society. Substandard services have not been well tolerated and paternalistic approaches in medical treatment are considered to be outmoded and inappropriate. Any dissatisfaction on the part of the patient towards medical services provided nowadays may easily trigger claims in the court of law. This changing trend has also fundamentally changed the behaviour of the courts towards the medical profession. Judicial and legislative interventions in medical practice have created more and more rights for the patients and consequently, corresponding legal duties for the medical profession to uphold. In the present healthcare setting, the medical profession will not be able to provide infallible services without knowledge of the legal standards which they have to adhere. Thus, educating future medical professionals with the fundamentals of law and ethics would ensure greater accountability, knowledge and personal commitment in providing medical services to the society as the ideals of professionalism not only require them to have the necessary expertise, dedication, respect, compassion, empathy, honesty, altruism, responsibility, integrity, self-improvement and accountability but also adherence to the demands of law and highest ethical standards.
\end{abstract}

Keywords: Medical education, Islamic input, Law, Ethics, Professionalism

\section{INTRODUCTION}

Technological advancements, reinforcement of patient autonomy, judicial interventions and demanding legal standards have contributed to the growing importance of medical law and ethics. As the role of the medical profession transgressed into areas with conflicting ethical and legal issues, medical professionals are facing constant dilemmas in making decisions that will result in the best course of patient care. The consequences of their actions and decisions can cause them to be legally responsible and accountable to their peers, their employers and ultimately, to the court of law. In order for them to make good decisions in executing their duties, it is imperative that they are able to integrate knowledge of ethical and legal aspects of health care and professional values into their practice. The ideals of professionalism require the medical practitioners to have the necessary expertise in all areas governing their profession, dedication, respect, compassion, empathy, honesty, altruism, responsibility, integrity, self-

Corresponding Author

Prof. Dr. Puteri Nemie Jahn Kassim (LLB)

Ahmad Ibrahim Kulliyyah of Laws

International Islamic University Malaysia

Jalan Gombak, Selangor.

Tel: +60193309935

email: nemie@iium.edu.my improvement and accountability. ${ }^{1}$ They should be able to execute their duties in such a way that patients feel safe and consequently, willing to be responsible when the course of action they choose falls below the standard demanded by law. Thus, educating the medical profession on the demands of law and high ethical standards through a holistic medical curriculum should be nurtured as early as possible. Inevitably, this would ensure greater accountability, knowledge and personal commitment in providing the best of care to their patients.

\section{The Changing Landscapes}

Although the role of healer remained fairly constant for the medical profession, their status and obligations changed in response to societal needs and professionalism. Society expects them to be answerable for the outcome of their medical treatment and they should also be subjected to punishment and regulations as any other profession. These changing landscapes through increase emphasis on patient autonomy and selfdetermination has created challenges for the medical profession in encountering a host of ethical dilemmas and legal problems in their daily practice. The fact that the medical profession deal with individuals' most precious commodities, that is, life and health, any mistake that results in death or disability will usually trigger claims in the court of 
law. This is due to the fact that patient usually find such mistakes hard to grasp as medicine is to cure and not otherwise. Such errors may transform the doctor from a noble figure to a hatred one. Patients tend to condemn mistakes made by doctors as mistakes could have been avoided if the doctor had taken proper care. Against this background, educating future medical professionals requires a curriculum that takes into account the changes surrounding the profession as well as the expectation and values of the society. ${ }^{2}$ Medical training should provide the appropriate learning experiences that promote development of medical professionalism and understanding of medical law and ethics. Most importantly, future medical professionals should be committed to maintain the respect and trust the society has upon the profession, which somehow has been eroded to a certain extent as a result of unethical practices by some of its members. ${ }^{3}$

\section{Understanding the Demands of Law in Medicine}

Legal principles develop in an ambience of rapidly changing societal values, as it is the function of the law to interpret and to reflect public attitudes. Legal as well as ethical dilemmas were always involved in medical developments but only recently they have been perceived as questions that could be taken to the courts for decision. Furthermore, highly publicized medical negligence cases by the mass media have clearly stifled and undermined public confidence towards the medical profession. The patient and society as a whole have high expectations and at times, perhaps exaggerated expectations. Dissatisfaction with the medical profession has led to a great increase in the number of complaints and cases brought to the courts. For instance, medico-legal complaints, potentially medico legal cases and cases filed in Malaysian courts are showing an increasing trend. According to the Malaysian Ministry of Health Annual Report 2010, the amount of compensation paid for court cases has risen from RM 1,224,990.00 in 2006 to RM $5,652,242.91$ in 2010. Payment for potential medico - legal cases and settled out of court has also risen from RM 25,000.00 in 2006 to RM 906,365.21 in 2010. This means that the total amount of compensation paid from 2006 to 2010 was RM $12,919,083.12$ with a noticeable increase in the amount of payment made in 2009 from RM $2,848,914.00$ to $\mathrm{RM} 6,558,608.12$ in $2010 .{ }^{4}$ Five to six-figure court awards are now becoming the trend for medical negligence cases, and with the notion of binding precedent that our legal system adheres to, it is unlikely that the number would go down in the future. While some victims undeniably deserved large awards, these escalating numbers do not indicate a healthy trend for the country nor doctors nor the society at large. The desire to litigate reflects all manner of dissatisfaction on the part of the patients with the conduct of the medical staff. There are clearly greater demands for public accountability and continuous quality improvement efforts are expected. Concerns about the quality of health care and the performance of healthcare professionals in the country have led to the establishment of Malaysian Society of Quality in Health (MSQH) in 1997 with the vision of advocating, promoting and supporting continuous quality improvement and safety in Malaysian healthcare arena. ${ }^{5}$ Programs for measurement of quality and improvement of healthcare professional's performance include clinical audit, peer review and continuing professional education.

The increasing demands of the law can also be seen from the decision of the Federal Court of Malaysia in the case of Foo Fio $\mathrm{Na} v \mathrm{Dr}$ Soo Fook Mun \& Anor. ${ }^{6}$ This case had abandoned the Bolam principle in favour of a more patient-centred approach by the reasonable prudent patient test as set forth in Rogers $v$ Whitaker. ${ }^{7}$ This clearly marked a change in the jurisprudential landscape in the law relating to informed consent which ultimately declared paternalistic approaches to the doctrine of informed consent as outmoded. Medical opinion about what risks are material are no longer conclusive as factors surrounding the patient circumstances will be taken into account in setting the standard of care in doctor's duty to disclose material risks. Since then, the judicial cases have developed with emphasis on respecting patient choice and self-determination, rendering patient autonomy into a dominant principle.

The Federal Court in the case of Foo Fio $\mathrm{Na}$ (2007) has declared that the practitioner is duty bound by law to inform his patient who is capable of understanding and appreciating such information of the risks involved in any proposed treatment so as to enable the patient to make a decision of whether to proceed with the proposed treatment with knowledge of the risks involved or decline to be subjected to such treatment. In light of the new Federal Court ruling, the Malaysian Medical Council (MMC) has introduced new 'Consent Guidelines' in 2013 to help the medical profession in adhering to the demands of law. Medical practitioners have to ensure that the consent taken from the patient has gone through a carefully planned process. According to the Guidelines, the 'requirements' for obtaining valid consent which include “(i) it must be given by a person with legal capacity, and of sufficient intellectual capacity to understand the implications of undergoing the proposed procedure; (ii) it must be taken in a language which the person understands; (iii) it must be given freely and voluntarily, and not coerced or induced by fraud or deceit (iv) it must cover the procedure to be undertaken; (v) the person must have an awareness and understanding of the proposed procedure and its known or potential risks; (vi) the person must be given alternate options to the proposed treatment or procedure; (vii) the person must have sufficient opportunity to seek further details or explanations about the proposed treatment or procedure; (viii) there must be a witness/interpreter, who may be 
another registered medical practitioner or a nurse, who is not directly involved in the management of the patient nor related to the patient or the medical practitioner, or any such person who can speak the language of the patient, to attest to the process during taking of the consent". "Informed consent is a medico legal requirement or procedure to ensure that a patient knows all of the risks and costs involved in a treatment". ${ }^{9}$ Therefore, medical practitioners "should assist the patient to understand the material provided and, if required, explain to the patient any information that he or she finds unclear or does not understand. The medical practitioner must offer the patient the opportunity to read the material and raise any specific issues of concern either at the time the information is given to the patient or subsequently. The medical practitioner must ensure that any preprepared material given to the patient is current, accurate and relevant to the patient. If such preprepared information material does not disclose all "material risks" either in general terms or otherwise, the medical practitioner must provide supplementary information on such "material risks" as are not disclosed, verbally. The likelier the risk, the more specific the details should be". ${ }^{10}$ Therefore, with the courts' greater recognition of individual autonomy in the law of informed consent, medical practitioners will be facing greater obligations in procuring the required consent. Medical education may have prepared the medical practitioner to treat the disease but not necessarily the ability to communicate fully and effectively with his patient in all encounters. This requires additional training and knowledge through appropriate education and continuing professional development, which will ultimately ensure that the informed consent processes undertaken accurately reflect the autonomous wishes of the patients which are required by the law.

\section{Resolving Ethical Dilemmas through Application of Islamic Medical Ethics}

Ethics is an intrinsic part of medical practice and shapes the contemporary medical profession. Currently, the medical profession is increasingly finding itself confronted with moral questions and ethical dilemmas on a consistent basis. In Islam, the term, ethics is used synonymously with 'Akhlaq', 'Adab' or 'Islamic virtues'."11 The Shari'ah, which contains all the different commandments of Allah to mankind, can be divided into three fields. The first is al-Ahkam al-l'tiqaddiyyah (sanctions relating to beliefs) such as the belief in Allah and the Day of Judgment. The second is al-Ahkam al-Akhlaqiyyah (sanctions relating to moral and ethics) such as the injunctions to tell the truth, sincerity and honesty and the third is al-Ahkam al-Amaliyyah (sanctions relating to the sayings and doings of the individuals and his relations with others). ${ }^{11}$ Thus, ethics is one of the main components of Shari'ah which every responsible Muslim should practice in their life, including the medical professionals. The primary sources of Islamic ethics are the divine guidance as reflected in Quranic revelations as well as in detailed teachings of the Prophet Muhammad (PBUH).$^{12}$ Consequently, the role of Islamic medical ethics is to guide the doctor to approach various ethical dilemmas that may develop throughout the duration of treatment he has with his patients. The three main areas in which ethical dilemmas in medical treatment are emerging are areas pertaining to 'End-of-life decisions', 'Consent' and 'Confidentiality'. With modern medical developments and their universal implementation, Muslim legal scholars are under pressure to respond to the moral and legal questions pertaining to health care of terminally ill patients. ${ }^{13}$ End-of-life issues are religiously, emotionally, and politically charged topic. Islam safeguards the sanctity of human life and regards life as a gift from God. The Quran stressed that, "It is He who has given you life, then He will cause you to die, and then will bring you back to life. Man is indeed ungrateful". ${ }^{14}$ Thus, since it is Allah SWT who bestows life, it is He who only has the right to take it away. No one has the right to terminate a life, except when applying one of Allah SWT's prescribed punishments.

There are also many verses in the Holy Qur'an, which forbids a person to kill another without proper justification. One such example is the verse that states, "Whoever kills a believer intentionally will be punished in hellfire where he will stay for eternity. He will incur the wrath of God, who will curse him and have a terrible penalty in store for him". ${ }^{15}$ These sources from the Qur'an and hadith illustrate the sanctity of human life, prohibition of killing a human being with no justification, and prohibition of killing one's self. However, it is not obligatory to administer medical treatment, which is ruled to be definitely useless or futile, such as if the patient is brainstem dead and there is no hope of recovery at all. Accordingly, withdrawal of life support system would be lawful for patients suffering from brain death. ${ }^{16}$ Without these life support machines, death would be inevitable for these patients and the existence of the machines merely prolong the process of death. However, when such medical treatment is withheld, the basic human rights of the patient which include being provided with food, drink, nursing care, and pain relief must still be provided and this can be done at home.

The patient should be allowed to die peacefully and comfortably, nevertheless there remains the duty to continue hydrating, nourishing and limiting pain. ${ }^{17}$ Furthermore, the Islamic Code for Medical and Health Ethics (IOMS, 2004) in Article 62 does not consider as euthanasia the termination of treatment "when its continuation is useless and this includes artificial respirators." Similarly, giving drugs to reduce severe pain does not come within the scope of "mercy killing" even if this drug may accelerate the patient's death. 
Thus, for Muslim medical practitioners, the establishment of ethical codes needs to conform to the basic tenets of aqidat al tawhid. The following essentials are necessary in shaping the conduct of medical practitioners with the mindset and framework of shari'ah, that is, (a) introduction of Islamic paradigms and concepts in general as they relate to medicine, mafahiim Islamiyah fi al Tibb (b) strengthening faith, iman, through the study of Allah's presence and greatness in the human body (c) appreciating and understanding the juridical, fiqh, aspects of health and disease, al fiqh al tibbi (d) understanding the social issues in medical practice and research and (e) professional etiquette, $a d a b$ al tabiib, from the Islamic perspective".19 Furthermore, since the Prophet's time, ethical controls and principles have been established for medicine to guide the medical profession's behaviour. As quoted by Abu Na'eem; the Prophet (PBUH) said that, "If a person who practices medicine while he is not known to be medically proficient, causes death or a lesser injury, he is held accountable." Therefore, educating future Muslim doctors within the Islamic framework and inculcating the correct mind-set that is in consonant with the Islamic worldview and principles is highly desirable as, "Doctor as an agent of healing and Allah is the Ultimate Healer". ${ }^{20}$ The idea of professionalism, calls for doctors to always ensure that they have the necessary expertise, good ethical conduct, good communication skills and exhibiting compassion. ${ }^{21}$ As advocate for their patients, they should be able to communicate with compassion so that patients feel safe and comfortable to receive their care. They are responsible to provide the best possible treatment to all their patients. This is the commitment of doctors to their patients that should be developed and nurtured during the training period. For Muslim medical practitioners, it is pertinent that Islamic medical ethics shape their conduct, which stems from mind-sets such as, "work as a form of worship or i'badah and 'Doctor as agent of healing and Allah is the Ultimate healer' as mentioned above. Additionally, they should also be familiar with the ethical principles of Maqasid and qawaid ai-Shari'ah as useful guide in resolving ethical dilemmas and legal problems apart from the conventional ethical principles of autonomy, beneficence, non-maleficence and justice.

\section{Shaping Medical Professionalism at an Early Stage}

A medical personnel has to instil core values of professionalism in his life such as dedication, respect, compassion and empathy, honesty, altruism, responsibility, integrity, self-improvement, magnanimity and accountability. ${ }^{1}$ To achieve this, it requires a rigorous application of behavioural and ethical standards developed over a the training period at the early stage of medical career. Consequently, medical students should be trained to develop attributes of medical professionalism during their undergraduate training, which would be in consonance with the philosophy, vision and mission of the institution, viz International Islamic University Malaysia (IIUM). Thus, a holistic medical curriculum that takes into account the realities of the society in terms of its needs and values is needed to train safe future doctors who are professionally competent and have good characters. $^{2}$ At IIUM, an integrated medical curriculum known as Islamic Input in Medical Program (IIMP) is in place to nurture doctors with good personal and professional development. Generally, inculcating professionalism begins on the first day a student joins the faculty during the orientation lecture, where they need to understand that they are tasked to develop the attributes of good medical professionalism during the training period and be committed to it. A holistic education process is necessary by combining lectures and workshop discussion of case studies that relates to the needs of the society and the demands of the law, religion and ethic. The learning experiences should provide opportunities for medical students to develop and enhance medical professionalism, leadership and characters of a safe doctor. They also need basic analysing skills of resolving ethical dilemmas that may conflict with legal standards, which require fundamental knowledge in both conventional and Islamic medical law and ethics This can be further enhanced by good professionalism and leadership skill. Additionally, as future Muslim doctors, they are responsible to live their lives as a good Muslim and facilitate Muslim patients on matters pertaining to basic $i$ 'badah and other religious matters especially during sickness. Learning medicine within the framework of Islamic teaching is considered an act of worship, i'badah, so much so that aiming to be safe doctors becomes a religious obligation. Developing the characters of a good Muslim and a good doctor should occur together. The Islamic mindsets such as 'Doctors as agent of healing, Allah is the Ultimate Healer', 'Purity of intention' and 'Work as 'ibadah', are powerful motivation for development of medical professionalism and characters of a good Muslim and a safe doctor. ${ }^{20}$

The patient expects a doctor to be able to communicate with compassion, which is the humane component of medicine, and feels safe and comfortable under his care. These are among some of the attributes of medical professionalism, which can be defined as "a body of qualities or features or competence, skills, behaviour, characteristic of a profession" that must be developed during medical training. A learning module called "Workshop on medical professionalism and proper physician etiquette" is organized at the beginning of the clinical training years to inculcate and enhance medical professionalism among medical students. It is a student-centred group activity and supervised by medical teachers, which involves discussion of real clinical scenarios or case studies that students would face as doctors and are expected to give their services in the utmost professional and ethical way. Through discussions of these cases, students 
learnt the importance of exercising professionalism and demonstrating proper etiquette in patient care. Furthermore, the experience gathered during these sessions is translated into real practice as they start seeing patients during the clinical rotations. ${ }^{21}$ The commitment towards professionalism is enhanced through ward rounds, bedside teachings and discussions in case reports, self-reflection and observation of professionalism among healthcare team members. These learning activities require them to decipher the meaning of and emulating good professionalism while avoiding the bad ones. Hopefully, these learning experiences would make them committed to developing and enhancing professionalism throughout the period of medical study and later in their career life as safe doctors. In short, the curriculum reflects the conscious effort to develop the ideal characters of a safe doctor and nurturing good professionalism within the framework of Islamic teachings. ${ }^{22}$ It represents a rigorous application of behavioural and ethical standards by instilling the core values inherent in Islamic law and ethic as "the sacred law of Islam is an all-embracing body of religious duties, the totality of Allah's commands that regulate the life of every Muslim in all its aspects". ${ }^{23}$

\section{Conclusion}

The teaching of medicine needs to develop a coherent and integrated approach to meet new societal demands and professionalism requires the trust of the patient and society. The commitment of the medical profession should continuously be built on morality and altruism. Developing the ideal characters of a safe doctor invariably involves integrating and infusing the demands of law and rigorous ethical standards that conforms to Islamic core values. Training future medical practitioners who are professionally competent and having good characters requires a well-thought curriculum that takes into account the realities of the society in terms of its needs and values. The learning experiences should provide opportunities for medical students to develop and enhance medical professionalism, leadership skills and characters of a good Muslim doctor. With these experiences, they should be able to acquire the skills to resolve ethical dilemmas which require fundamental knowledge in medical law and ethics and enhanced by good professionalism and leadership skill.

\section{References}

1. Shaharom MH. Teaching medical professionalism: An Islamic approach. FIMA Year Book 2009; 57-64.

2. Osman A. Workshop for teaching medical professionalism at the Kulliyyah of Medicine, IIUM. FIMA Year Book 2009; 65-72

3. Kew ST. Medical Professionalism and Ethics. Newsletter of the Academy of Medicine of Malaysia 2005; Vol. 14 No 4.
4. Annual Report Ministry of Health Malaysia 2010 (online): Available at: vlib.moh.gov.my/cms/ documentstorage/com.tms.cms.document/ AnnualReport2010.pdf. Accessed February 15, 2016.

5. Malaysian Society for Quality in Health (online). Available at www.msqh.com.my. Accessed February 15, 2016.

6. Foo Fio $\mathrm{Na} v$ Dr Soo Fook Mun and Anor. 1, 593 MLJ. 2007.

7. Rogers v Whitaker (1992) 175 CLR 479, (1992) 109 ALR 625, (1992) 67 ALJR 47.

8. Malaysian Medical Council Consent For Treatment (online). Available at http:// www.mmc.gov.my/v1/docs/Consent\% 20Guidelines\%2015012013.pdf. Accessed February 17, 2016

9. Ibid. at provision 8(c).

10. Ibid. at provision 13.

11. Mohamad Akram Laldin. Islamic Law, An Introduction. 4th ed. IIUM Press: 2014.

12. Fatimah Abdullah (Ed). Islamic Ethics and Character Building. IIUM Press: 2014.

13. Sachedina A. End of life: The Islamic View. The Lancet 2005; 366. 774-779.

14. The Glorious Quran, Chapter 22, Verse 66.

15. The Glorious Quran, Chapter 4, Verse 93.

16. Yusuf al-Qardawi, Fatawa Mu'asirah, Dar alWafa il al-Tiba'ah wa al-Nashr wa al-Tawzi. Egypt 1993; Vol. 2, pp. 527-529.

17. Athar S, Fadel HE, Ahmad WD et al. (2005). IMANA Ethics Committee. Medical Ethics: the IMANA Perspective. J Islam Med Assoc.; 37:3342. Available at http://jima.imana.org/article/view/5528. Accessed March 30, 2016.

18. Islamic Organisation for Medical Sciences (IOMS) (2004).

http://www.islamset.com/ioms/Code2004/ind ex.html. 1-61.

19. Kasule OH. (2009). A 13-Year Experience of Integrating Islamic Values In The Medical Curriculum In South-East Asia. FIMA Year Book 2009; 1-28.

20. Osman A. Integrating Islamic values in medical teaching curriculum: IIUM experience. Bangladesh Journal of Medical Science 2013; 12:117-20.

21. A Student Guide to Workshop on Medical Professionalism and Proper Physician Etiquette. Kulliyyah of Medicine (IIUM); 2008.

22. A Student Guide to Workshop on Obstetric Analgesia and Reflection on Professionalism. Kulliyyah of Medicine (IIUM); 2012.

23. Schacht, J. An Introduction to Islamic Law, Oxford: Clarendon Press, 1964. 